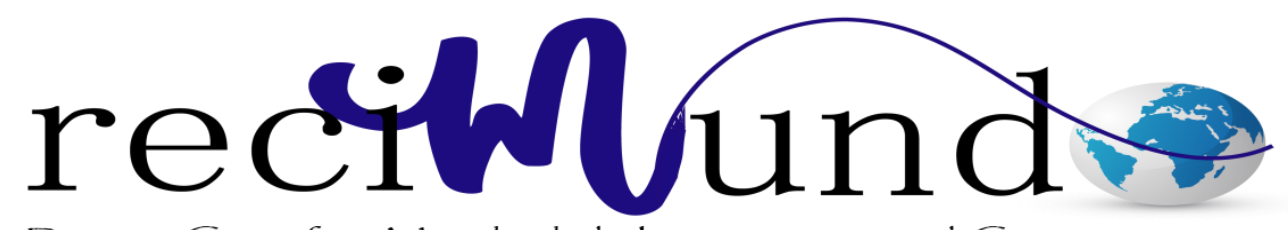

Revista Científica Mundo de la Investígación y el Conocimiento

\author{
Jean Paolo Zea Morales ${ }^{\text {a }}$; Wiliam Juvenal Zea Pizarro b; Víctor Iván Vaccaro \\ Macías ${ }^{\text {c }}$ Elsy Avalos Moreno ${ }^{\mathrm{d}}$
}

Los Aminoácidos en el cuerpo humano

Revista Científica Mundo de la Investigación y el Conocimiento. Vol. 1 núm., 5, diciembre, 2017, pp. 379-391

DOI: $10.26820 /$ recimundo/1.5.2017.379-391

Editorial Saberes del Conocimiento
a.
b. Carrera de Medicina; Universidad de Guayaquil.
c. Carrera de Medicina; Universidad de Guayaquil.
d. Carrera de Medicina; Universidad de Guayaquil. 


\section{Los Aminoácidos en el cuerpo humano}

Vol. 1, núm. 5., (2017)

Jean Paolo Zea Morales; Wiliam Juvenal Zea Pizarro; Víctor Iván Vaccaro Macías; Elsy Avalos Moreno

\section{RESUMEN}

En la naturaleza existen más de 300 diferentes aminoácidos, de los cuales el ser humano utiliza solo 20. Los de mayor interés son los que forman parte estructural de las proteínas, ya que son las moléculas más abundantes y tienen una gran diversidad en sus funciones, puesto que forman parte de enzimas, hormonas, neurotransmisores. El objetivo de este estudio es describir las funciones primordiales de los aminoácidos en el cuerpo humano, siendo necesario para ello recurrir a la definición de varios conceptos fundamentales relacionados a dicho tema, tales como definición, estructura, clasificación y funciones. Esta investigación se basa en un estudio de tipo documental, a nivel exploratorio-descriptivo, sobre los aminoácidos en los seres humanos, para ello se realizrá una laboriosa búsqueda en publicaciones a través de medios físicos y electrónicos, tales como libros, e-book, revistas especializadas, foros, simposios, páginas web y demás fuentes de información legal, oficial y respaldada por profesionales y científicos en la materia de entes públicos o privados, oficiales o particulares, nacionales e internacionales, en idioma castellano, relacionados con el tema de los aminoácidos en los seres humanos, publicados en cualquier país hasta diciembre de 2017. Finalmente, se analizaran las propiedades y características de los aminoácidos, según sus tipos o clasificación que guarden relación especial con los del cuerpo humano.

Palabras claves: Aminoácidos; proteinas; enzimas, tejidos, metabolismo. 


\title{
Los Aminoácidos en el cuerpo humano
}

Vol. 1, núm. 5., (2017)

Jean Paolo Zea Morales; Wiliam Juvenal Zea Pizarro; Víctor Iván Vaccaro Macías; Elsy Avalos

Moreno

\begin{abstract}
In nature there are more than 300 different amino acids, of which the human being uses only 20 . The most interesting are those that are structural part of proteins, since they are the most abundant molecules and have a great diversity in their functions, since they are part of enzymes, hormones, neurotransmitters. The objective of this study is to describe the primordial functions of amino acids in the human body, being necessary to resort to the definition of several fundamental concepts related to this subject, such as definition, structure, classification and functions. This research is based on a documentary, exploratory-descriptive study about amino acids in humans, for which a laborious search will be made in publications through physical and electronic means, such as books, e-book, specialized magazines, forums, symposiums, web pages and other sources of legal information, official and supported by professionals and scientists in the field of public or private, official or private entities, national and international, in Spanish, related to the subject of amino acids in humans, published in any country until December 2017. Finally, the properties and characteristics of amino acids will be analyzed, according to their types or classification that have special relationship with those of the human body.
\end{abstract}

Key words: Amino acids; proteins; enzymes, tissues, metabolism. 


\section{Los Aminoácidos en el cuerpo humano}

Vol. 1, núm. 5., (2017)

Jean Paolo Zea Morales; Wiliam Juvenal Zea Pizarro; Víctor Iván Vaccaro Macías; Elsy Avalos Moreno

\section{Introducción.}

A principios del siglo XIX, época en que por primera vez los científicos dirigen su atención a la nutrición, rápidamente descubren que los productos naturales que contenían nitrógeno eran esenciales para la vida de los animales, siendo entonces en 1839 que el químico danés Gerardus Mulder acuña para esta clase de compuestos el término: Proteína (del griego: proteios, primario), y a pesar de que los químicos fisiólogos de esa época ya habían aislado en 1830 dichos compuestos proteicos, ninguno de ellos se habían dado cuenta de que las proteínas estaban formadas en realidad por componentes más pequeños, conocidos hoy como: los aminoácidos. De hecho, durante muchos años se creyó que las sustancias provenientes de las plantas -incluidas las proteínas- se incorporaban enteras en los tejidos animales. Este concepto erróneo se abandonó a un lado cuando finalmente se ilustró el proceso de la digestión, con el que demostró que las proteínas ingeridas se separaban en componentes más pequeños contentivos de aminoácidos, siendo entonces cuando dichos científicos dirigen su atención a las diversas cualidades de estos esenciales compuestos. (Voet, Greenwald, \& Pratt, 2007)

De todos los aminoácidos que se conocen en la naturaleza, sólo veinte (20) forman parte de las proteínas. Desde el inicio de su estudio, pasaron más de cien años, para poder conocer las estructuras de todos ellos: siendo en 1.806 que se descubrió, en el espárrago, el primer aminoácido que, por ende, recibió el nombre de asparragina; y sólo hace relativamente pocos años, en 1.938, fue descubierto el último de los veinte, la treonina. (Lehninger, Cox, \& Nelson, 2007) 


\section{Los Aminoácidos en el cuerpo humano}

Vol. 1, núm. 5., (2017)

Jean Paolo Zea Morales; Wiliam Juvenal Zea Pizarro; Víctor Iván Vaccaro Macías; Elsy Avalos

Moreno

Los aminoácidos, desde un punto de vista estructural, son los elementos componentes de las proteínas y éstas a su vez son las estructuras que componen cualquier tejido vivo, su presencia es tan relevante, que se les conoce como los constructores de la vida. Desde un punto de vista funcional, los aminoácidos cumplen importantes funciones, entre ellas citar su intervención en el metabolismo energético, y su acción anti estrés minimizando los efectos nocivos que provocan ciertas enfermedades. (Slogar España, 2017)

Es importante aclarar que existen varios criterios para clasificar en diferentes grupos a los aminoácidos: ya sea por su polaridad, por su carga eléctrica, por su afinidad con el agua, por su actividad giratoria en el plano de luz polarizada, por su síntesis en las células, por su pH, entre otros (Melo \& Cuamatzi, 2007) no obstante, y en pro del enfoque de esta obra, se hará mención particular a la concepción clásica de la clasificación nutricional de los aminoácidos, la cual los divide en dos (02) categorías: Esenciales (o Indispensables) y No Esenciales (o Dispensables). Los nueve aminoácidos esenciales (histidina, isoleucina, leucina, iisina, metionina, fenilalanina, treonina, triptófano y valina) constituyen un grupo cuyo esqueleto carbonado no puede ser sintetizado a partir de moléculas simples por los seres humanos y, por lo tanto, deben proveerse con la dieta. (Gil, 2010)

\section{Materiales y métodos.}

Esta investigación se basa en un estudio de tipo documental, a nivel descriptivo sobre los aminoácidos en el cuerpo humano. 


\section{Los Aminoácidos en el cuerpo humano}

Vol. 1, núm. 5., (2017)

Jean Paolo Zea Morales; Wiliam Juvenal Zea Pizarro; Víctor Iván Vaccaro Macías; Elsy Avalos Moreno

Según (Morales, 2003) la investigación documental tiene la particularidad de utilizar como una fuente primaria de insumos, mas no la única y exclusiva, el documento escrito en sus diferentes formas: documentos impresos, electrónicos y audiovisuales. la investigación documental es un procedimiento científico, un proceso sistemático de indagación, recolección, organización, análisis e interpretación de información o datos en torno a un determinado tema. Al igual que otros tipos de investigación, éste es conducente a la construcción de conocimientos. Ha de entenderse que los estudios descriptivos "buscan especificar la propiedades, las características y los aspectos importantes del fenómeno que se somete a análisis" (Gómez, 2006)

Así mismo, de la literatura antes referida, sirve de apoyo para fundamentar éste trabajo investigativo, puesto que en dicha fuente se explica que los estudios descriptivos se enfocan en recabar datos que muestren cómo se manifiesta un hecho, contexto, evento, fenómeno o situación. De la misma manera, el autor refiere que la descripción puede ser más o menos profunda, y en cualquiera de los casos se basa en la recolección de datos sobre éste y su contexto, en relación específica con las investigaciones de variable cualitativa, como es el presente caso

\section{Resultados.}

\section{Aminoácidos}

"Son los componentes esenciales de las proteínas que forman los tejidos, las enzimas y otros compuestos imprescindibles del organismo, como la sangre hormonas, anticuerpos, material genético, entre otros.” (Naclerio, 2006) 


\section{Clasificación de los aminoácidos}

Es de gran importancia contar con proteínas en la dieta, como una fuente de aminoácidos; algunos de estos son realmente indispensables para los mamíferos, ya que éstos no pueden sintetizar sus esqueletos carbonados. Los seres humanos, así como las ratas, son incapaces de sintetizar nueve de los veinte aminoácidos estándar que se utilizan en la síntesis de proteínas, estos aminoácidos, llamados esenciales (histidina, isoleucina, leucina, lisina, metionina, fenilalanina, treonina, triptofano y valina), pueden ser elaborados por las plantas y diversos microorganismos a través de rutas metabólicas complejas. Aquellos aminoácidos que si es posible sintetizarse llaman aminoácidos no esenciales (alanina, arginina, asparagina, ácido aspártico, citrulina, cisteina, cistina, ácido gama-aminobutírico, ácido glutámico, glutamina, glicina, ornitina, prolina, serina, taurina y tirosina).

\section{Aminoácidos esenciales}

Los mamíferos los obtienen principalmente de las proteínas de la dieta que se digieren en el intestino para que sean liberados y posteriormente se absorban y puedan servir como precursores de proteínas u otros materiales biológicos. Los grupos amino de los aminoácidos ingeridos en exceso con respecto a los requerimientos, son extrados por transaminación, y los esqueletos carbonados que quedan son catabolizados a intermediarios que es posible oxidar para liberar energía o convertirse en combustibles metabólicos como la glucosa o aminoácidos glucogénicos o cetogénicos: estos eventos tienen lugar principalmente en el hígado. (Melo \& Cuamatzi, 2007) 


\section{Los Aminoácidos en el cuerpo humano}

Vol. 1, núm. 5., (2017)

Jean Paolo Zea Morales; Wiliam Juvenal Zea Pizarro; Víctor Iván Vaccaro Macías; Elsy Avalos Moreno

\section{Aminoácidos no esenciales}

Son aquellos que sintetizan las células de los mamíferos y son precursores de otros constituyentes celulares no proteicos. En cuanto a la arginina, ésta es considerada como un aminoácido esencial para los mamíferos, porque se requiere en la dieta durante el crecimiento de los individuos jóvenes. Algunos aminoácidos pueden ser descritos como no esenciales porque es posible formarlos a partir de aminoácidos esenciales: un ejemplo es la tirosina, que se puede elaborar a partir de fenilalanina. Así pues, si la dieta solo incluye la fenilalanina suficiente para satisfacer el requerimiento de este aminoácido, entonces puede presentarse una deficiencia de tirosina. (Melo \& Cuamatzi, 2007)

\section{Deficiencia de aminoácidos}

(Licata, 2017)refiere que:

“...de acuerdo a sus necesidades, el organismo produce las diferentes clases de proteínas Pero si le llegase a faltar alguno de los aminoácidos esenciales, esa síntesis no se realizaría adecuadamente. Esto ocasionaría una insuficiencia de proteínas trascendentales para el organismo, generando problemas tales como indigestión, depresión o retraso en el crecimiento"

Así mismo, asegura que:

"la deficiencia de aminoácidos será debido a una dieta desequilibrada e inadecuada en proteínas. Una dieta que no nos proporcione una cantidad suficiente de aminoácidos esenciales, conducirá a padecer alguna enfermedad o trastorno; sin embargo, existen 


\section{Los Aminoácidos en el cuerpo humano}

Vol. 1, núm. 5., (2017)

Jean Paolo Zea Morales; Wiliam Juvenal Zea Pizarro; Víctor Iván Vaccaro Macías; Elsy Avalos

Moreno

situaciones donde a pesar de tener una dieta adecuada, la deficiencia aminoácidos ocurre de todas formas. Esa falta puede provocarse por: mala absorción de nutrientes, infecciones, traumas, estrés, consumo de drogas, edad o desequilibrio de otros nutrientes"

Para evitar confusiones, es importante aclarar que la solución no es la ingesta excesiva de proteínas, ya que no sería saludable, y se produciría una sobrecarga en los riñones y en el hígado. Siempre se debe ingerir una cantidad adecuada de proteínas. Así, el hígado metabolizará correctamente el amoníaco, generado por el mismo metabolismo proteico, y de esta manera no será perjudicial para nuestra salud. Para que el amoníaco no se acumule, el hígado lo convierte en urea, compuesto de menor toxicidad y luego es filtrado por los riñones para finalmente ser excretado.

\section{Funciones de los Aminoácidos}

En nuestro organismo se encuentra un número considerable de complejos proteínicos. Estas proteínas se sintetizan endógenamente a partir de aminoácidos. Generalmente, todos los aminoácidos intervienen en el mantenimiento de los biosistemas; en particular, y como constituyentes de las proteínas, cumplen las siguientes funciones:

- Componentes estructurales de tejidos, células y músculos.

- Promueven el crecimiento y reparación de tejidos y células.

- Contribuyen a las funciones sanguíneas.

- Intervienen en los procesos de síntesis de enzimas digestivos. 


\section{Los Aminoácidos en el cuerpo humano}

Vol. 1, núm. 5., (2017)

Jean Paolo Zea Morales; Wiliam Juvenal Zea Pizarro; Víctor Iván Vaccaro Macías; Elsy Avalos Moreno

- Constituyentes de las hormonas esenciales para la reproducción.

- Intervienen en el metabolismo energético.

Por sí mismos, los aminoácidos, son imprescindibles por las funciones que libran, ya que son indispensables para que los otros nutrientes sean correctamente metabolizados y absorbidos, y son necesarios para un funcionamiento idóneo de las vitaminas y de los minerales.

Dicho esto, los aminoácidos se consideran moléculas vitales, y como tales es de extremada importancia que el organismo disponga de los mismos en los niveles óptimos. (Slogar España, 2017)

Existen 28 aminoácidos conocidos, que combinados de diferentes formas crean cientos de proteínas. El $80 \%$ de estos nutrientes se producen en el hígado, son los llamados aminoácidos no esenciales, y el 20\% restante debe proveerse a través de la dieta y reciben el nombre de aminoácidos esenciales. (Licata, 2017)

Es importante destacar, desde el punto de vista Bioquímico, que los aminoácidos tienen diferentes funciones en el organismo pero ante todo sirven como unidades básicas de los péptidos y de las proteínas. En el código genético (ADN) solo se consideran los veinte aminoácidos proteicos; estos veinte aminoácidos son los que se encuentran regularmente en las proteínas y en algunos casos sufren modificaciones después de su incorporación a ellas (cambios postraduccionales. En los lípidos también se encuentran aminoácidos o sus derivados como unidades básicas, por ejemplo la serina en los fosfolípidos y la glicina en las sales biliares. Algunos aminoácidos se desempeñan como neurotransmisores y otros son precursores de 


\section{Los Aminoácidos en el cuerpo humano}

Vol. 1, núm. 5., (2017)

Jean Paolo Zea Morales; Wiliam Juvenal Zea Pizarro; Víctor Iván Vaccaro Macías; Elsy Avalos

Moreno

neurotransmisores, de mediadores o de hormonas. Los aminoácidos son constituyentes importantes de la nutrición (algunos son inclusive esenciales). Determinados aminoácidos forman precursores para otros metabolitos, Como por ejemplo para la glucosa en la gluconeogénesis, para las bases de purinas y pirimidinas, para el hemo y para otras moléculas. Ciertos aminoácidos no proteicos funcionan como intermediarios en la síntesis y en la degradación de otros aminoácidos proteicos y en el ciclo de la urea. (Koolman \& Röhm, 2004)

\section{Conclusiones.}

Luego de interpretar y analizar toda la literatura consultada, se puede deducir que pesar de que diversos estudios efectuados sobre la efectividad de los aminoácidos han arrojado resultados muy positivos, su reconocimiento aún es insuficiente en la mayoría significativa de las ciencias donde generan un gran impacto, con excepción en algunas disciplinas básicas, y no por ello menos importantes, como lo son las de nutrición y bioquímica, diferenciando que hay la necesidad de generar más estudios demostrativos sobre lo positivo de estos complementos en las áreas de medicina, por ejemplo. Esto se sostiene debido a que, como ya se ha desarrollado ut supra, primordialmente, las proteínas están compuestas por aminoácidos que son a su vez necesarios para la constitución de proteínas estructurales como el colágeno, las enzimas, la coagulación, los anticuerpos, el transporte de moléculas, la masa muscular y las hormonas. Enfática y categóricamente es posible defender la idea de que:

- Los aminoácidos representan un rol fundamental en la medicina nutricional, por ser los encargados de regular todos los procesos que ocurren dentro del organismo humano. 


\section{Los Aminoácidos en el cuerpo humano}

Vol. 1, núm. 5., (2017)

Jean Paolo Zea Morales; Wiliam Juvenal Zea Pizarro; Víctor Iván Vaccaro Macías; Elsy Avalos Moreno

- Los aminoácidos arginina, glutamina, lisina, metionina y taurina son inmunosupresores y ayudan a las personas con las defensas bajas, esto guarda relación particularmente con personas vegetarianas y pacientes de enfermedades crónicas del hígado o de los riñones, son un grupo con un alto riesgo de déficit de aminoácidos.

- Las macromoléculas más importantes (proteínas y ácidos nucleicos) y otras biomoléculas de gran significado fisiológico, como algunos neurotransmisores, grupos prostéticos y coenzimas entre otras, tienen como unidades fundamentales a los aminoácidos, o derivados de éstos

- La composición de los aminoácidos en la dieta no necesariamente corresponde a la composición de las proteínas que son sintetizadas en las células humanas, ocurren numerosas interconversiones para producir un balance apropiado. Todas estas interconversiones están dadas por el metabolismo.

- El metabolismo de los aminoácidos está estrechamente relacionado con los procesos biológicos fundamentales.

\section{Bibliografía.}

Gil, Á. (2010). Tratado de nutrición: Bases Fisiológicas y Bioquímicas de la Nutrición. (2da. ed.). Madrid: Editorial Médica Panamericana.

Gómez, M. (2006). Introducción a la metodología de la investigación científica. (1ra.). Córdoba, Argentina: Brujas.

Koolman, J., \& Röhm, K.-H. (2004). Bioquímica: texto y atlas. (3ra. ed.). Madrid: Médica Panmericana, S.A.

Lehninger, A., Cox, M., \& Nelson, D. (2007). Principios de Bioquímica. New York: Omega. 


\section{Los Aminoácidos en el cuerpo humano}

Vol. 1, núm. 5., (2017)

Jean Paolo Zea Morales; Wiliam Juvenal Zea Pizarro; Víctor Iván Vaccaro Macías; Elsy Avalos

Moreno

Licata, M. (2017). Aminoácidos, nutrientes esenciales para la vida. . Obtenido de Recuperado de: https://www.zonadiet.com/nutricion/aminoacidos1.htm

Melo, V., \& Cuamatzi, O. (2007). Bioquímica de los procesos metabólicos. (2da. ed.). Mexico: Reverté Ediciones, S.A.de C.V.

Morales, O. (2003). www.saber.ula.ve. Fundamentos de la investigación documental y la monografía. Mérida, Mérida, Venezuela. Recuperado el 25 de 11 de 2017, de www.saber.ula.ve:

Recuperado

de: https://www.saber.ula.ve/bitstream/123456789/16490/1/fundamentos_investigacion.pdf

Naclerio, F. (2006). g-se.com. Recuperado el 25 de 11 de 2017, de Recuperado de: https://gse.com/utilizacion-de-las-proteinas-y-aminoacidos-como-suplementos-o-integradoresdieteticos-766-sa-P57cfb27181ef9

Slogar España. (15 de 11 de 2017). Casa Pía. Los Aminoácidos - Información Completa. Madrid, España. Obtenido de https://dietetica.casapia.com/los-aminoacidos/los-aminoacidosinformacion-completa.html

Voet, D., Greenwald, J., \& Pratt, C. (2007). Fundamentos De Bioquímica. Madrid: Médica Panamericana. 